\title{
CONSIDERAÇÕES SOBRE A NOÇÃO DE IMITAÇÃO EM PAOLO PINO E LODOVICO DOLCE
}

Rejane Maria Bernal Ventura

Faculdade de Filosofia, Letras e Ciências Humanas - FFLCH -USP

Esta comunicação aborda um aspecto relacionado à pesquisa de Doutoramento intitulada "O Dialogo di Pittura de Paolo Pino, o Dialogo della Pittura Intitolato I'Aretino, de Lodovico Dolce e a reflexão sobre a arte em Veneza do século XVI", desenvolvida no Departamento de Filosofia da FFLCH-USP, sob orientação do Prof. Dr. Victor Knoll.

O objetivo deste estudo é circunscrever uma teoria da arte no âmbito da pintura veneziana, em contraposição aos princípios estéticos que vigoravam na região Tosco-romana, entre os séculos XV e XVI, tomando como objeto de estudo dois importantes tratados artísticos do período: o Dialogo di Pittura, de Paolo Pino (1548), e o Dialogo della Pittura intitolato l'Aretino, de Lodovico Dolce (1557). A pesquisa pretende responder a três questões que consideramos relevantes para o estudo da arte do século XVI: 1) Existe uma teoria artística específica à pintura veneziana na primeira metade do século XVI? 2) Quais são as características estéticas que a diferenciam de uma teoria da pintura na região Tosco-romana? 3) E quais os conceitos filosóficos inerentes a essas duas teorias?

As referidas questões serão respondidas a partir da investigação de quatro problemas estéticos suscitados pela leitura dos dois tratados. São eles: a) o conceito de mimesis; b) a noção de beleza ideal em sua relação com a proporção harmônica unida à graça, conceito este que reflete a influência ao mesmo tempo de concepções aristotélicas e platônicas; c) as noções correlatas de juízo e gosto; d) a partição da pintura e a defesa do primado da cor em oposição ao desenho.

A fim de atingirmos esse propósito, levaremos em consideração os argumentos constantes nos textos e as fontes com as quais os autores dialogam, no sentido de que estas duas instâncias possibilitem delinear alguns conceitos estéticos. E por meio deles constatar o entrelaçamento de certas noções pertencentes aos sistemas filosóficos de Platão e Aristóteles.

O escrito de Paolo Pino enfoca uma argumentação dialógica com o Da Pintura de Leon Battista Alberti, traduzido para o italiano vulgar em 1547 por Lodovico Dominichi. Por intermédio da conversa entre dois pintores, um veneziano e outro florentino, Pino discorre sobre as principais preceptivas em debate pelos artífices e letrados do período, tais como: 
beleza natural versus beleza artística, cânones de proporção da figura humana, perspectiva, pintura enquanto arte liberal, conceito de pintura e suas partições, técnicas pictóricas, o cotejo entre pintura e escultura, a doutrina ut pictura poesis, e normas para o pintor perfeito.

O tratado de Lodovico Dolce, por sua vez, a despeito de também argumentar sobre algumas temáticas presentes no texto de Pino, tem como principal escopo traçar um cotejo entre os maiores pintores do período em sua opinião: Michelangelo, Rafael e Ticiano. No diálogo entre o escritor Pietro Aretino e o gramático toscano Giovan Fabrini, Dolce tece uma sutil crítica à atitude de Vasari de defender a divindade de Michelangelo, por meio de sua biografia publicada em sua obra máxima Le Vite dei più eccellenti pittori. scultori e architetti.

O preceito da imitação é uma das matérias mais importantes discutidas nos dois escritos.

É sabido que, enquanto conceito fundamental da teoria das artes prescrito na Antiguidade Clássica, a noção da mimesis foi ponto relevante de debate entre os artistas de várias épocas e tema corrente no corpus da Literatura Artística. A partir dos séculos XV e XVI, a mimesis aristotélica, vem se entrelaçar ao conceito da Idea platônica. O preceito do "imitar" nesse período tinha por objetivo instituir a imagem de beleza perfeita da figura humana, em particular a feminina. Duas problemáticas se insurgem a partir desta questão. No caso da pintura em particular, a beleza originar-se-ia da pura imitação das formas naturais pelo pintor, ou ela nasceria de uma idéia pré-concebida representada em sua mente por consequência do estudo da natureza? No primeiro momento a imitação perfaz-se por uma tal similaridade às formas, volumes e proporções presentes nas criaturas da natureza, sejam animadas ou inanimadas, com todas as suas imperfeições que, ao serem figuradas num plano bidimensional pelo pintor, tornam-se como que reais a ponto de causar ilusão nos olhos de quem as observa. No segundo momento, a imitação realizada pelo pintor perfaz-se por uma correção das partes consideradas imperfeitas. Ele representa os elementos não como se apresentam à vista, mas como deveriam ser, perfeitos. Nesse sentido, a imitação efetua-se por superação da natureza. Estes dois momentos encontram-se em ambos os tratados.

A noção de mimesis no diálogo de Paolo Pino é introduzida pela argumentação sobre o cotejo entre beleza natural versus artística, com o 
propósito de estabelecer um paradigma de beleza feminina. A discussão apresenta-se sob dois aspectos: o primeiro, a representação similar das formas naturais com todos os seus acidentes ${ }^{1}$. O segundo, a seleção das partes mais belas desta mesma natureza, a fim de atingir aquele paradigma. De acordo com Pino não há beleza perfeita em sua completude num só elemento da natureza. Ela está disseminada por todas as obras naturais. Cabe portanto ao pintor fazer uma seleção das partes mais belas e uni-las num todo em sua obra, a fim de conceber a beleza feminina perfeita (a anedota de Zêuxis, tantas vezes mencionada nos tratados, é o caso exemplar para o argumento) $)^{2}$.

Concomitante ao escrito por Paolo Pino, Lodovico Dolce afirma que o pintor deve representar em sua arte as coisas que imita da natureza, em toda sua similitude ${ }^{3}$. Do mesmo modo declara que pintura não é outra coisa senão a imitação da natureza, e o pintor que mais se aproximar de suas obras, mais perfeito mestre será4. Sua argumentação apresenta três momentos: a imitação similar da natureza e eleição de suas partes mais belas (em acordo com Pino), o que implica superar a natureza ${ }^{5}$ e um terceiro momento específico do diálogo, em que prescreve ao pintor o

1 PINO, Paolo. Dialogo di Pittura di Messer Paolo Pino nuovamente dato em luce. In Vinegia per Pauolo Gherardo, MDXLVIII. Edição fac-símile de 1548 (com nota de Giorgio Nicodemi), Milão, 1945, p. 4, 5, 10: "altra regola non hanno i pittori, ch'imitare le cose vive e proprie" "Ditemi? Se ciascui ha naturalmente la cognitione delle cose naturali, meglio dovrebbe intendere la pittura, come imagine del natural" "[...] et dato che tutte l'arti imitano la natura, questa sopra tutte l'altre, con maggior integrità imita tutte le cose naturali [...]".

2 PINO, Paolo, op. cit., p. 5: "Veramente tutte le fatture naturali patiscono oppositioni. Il che causa l'impotencia della matéria, nelle qual essa natura imprime l'opere sue. E per non incorrere nell'imperfettione, imitate Zeusi, che volendo appresso li Crotoniati dipignere una Venere, elesse tra tutte le giovanette della città cinque vergini, tra beltà delle quali soppliva all'integrità della sua Venere, raccogliendo da uma di quelle gli occhi, dall'altra la bocca, e dall'altra il petto e in tal guisa reduceva a perfettione l'opera sua".

3 DOLCE, Lodovico. Dialogo della Pittura, intitolato L'Aretino. in Trattati d'Arte del Cinquecento - Fra Manierismo e Controriforma. Vol. I. Bari, Gius. Laterza e Figli, 1960, p. 153: 'L' ufficio adunque del pittore è di rappresentar com l'arte sua qualunque cosa, talmente simile alle diverse opere della natura, ch'ella paia vera. E quel pittore, a cui questa similitudine manca, non è pittore, et all'incontro colui tanto più è migliore e più eccellente pittore, quanto maggiormente le sue pitture s'assomigliano alle cose naturali".

${ }^{4}$ Idem, ibidem, p.152: "Dico adunque la pittura, brevemente parlando, non essere altro che imitazione della natura; e colui che più nelle sue opere le si avicina, è più perfetto maestro [...] aggiungo che il pittore è intento a imitar per via di linee e di colori, o sia in un piano di tavola o di muro o di tela, tutto quello che si dimostra all'occhio; et il poeta col mezzo delle parole va imitando non solo ciò che si dimostra all'occhio, ma che ancora si rappresenta all'intelletto. Laonde essi in questo sono differenti, ma simili in tante altre parti, che si possono dir quasi Fratelli".

5 Idem, ibidem, p. 172: "Deve adunque il pittore procacciar non solo d 'imitar, ma di superar la natura". 
estudo das esculturas antigas, cuja perfeição pode auxiliá-lo a corrigir muitos defeitos da natureza ${ }^{6}$.

Estes aspectos que caracterizam o preceito da mimesis nos dois autores, abarcam, segundo Luigi Grassiำ, mudanças semânticas sofridas pelo conceito, decorrentes da influência de Platão e Aristóteles, as quais tomam ao longo da história, caminhos contraditórios ou no caso do século XVI, tornam-se confluentes. Estas duas vias da imitação tocam em dois conceitos aristotélicos, "verdadeiro" e "verossímil", e no conceito de Idea platônico. A primeira via, imitação similar das coisas naturais, está ligada aos elementos que compõem a natureza com suas perfeições e acidentes, ou seja, aos acontecimentos, histórias, fatos que se apresentam diante dos olhos, correspondendo ao que é o "verdadeiro".

A segunda via, imitação por superação, consiste no ato de imitar não os fatos verdadeiros, mas como deveriam ser, ou aqueles que seriam plausíveis de acontecer, no âmbito do verossímil ou do necessário, seguindo leis de verossimilhança como unidades de tempo, lugar e ação. Estas categorias teriam a tarefa de imprimir coerência, disciplina e ordem naquele "verdadeiro" da natureza que não o apresenta ${ }^{8}$.

Quanto à noção da Idea, na medida em que o pintor supera a natureza, corrigindo-lhe os defeitos ou acidentes, elencando as melhores partes para compor sua obra, ele está na verdade procurando um paradigma-forma-idéia que está além do mundo natural. O que revela suas imperfeições. Esta foi uma das razões pelas quais Platão imputou às "artes da imitação" o papel de simulacros, uma vez que ao "corrigirem" a natureza, elas deformariam o "real", deixando de ser verdadeiras para

${ }^{6}$ Idem, ibidem, p. 176: "E parte se debbono imitar le belle figure di marmo o di bronzo de' maestri antichi; la mirabile perfezzion delle quali chi gusterà e possederà a pieno, potrà sicuramente corregger molti difetti di essa natura".

7 GRASSI, Luigi e PEPE, Mario. Dizionario dei Termini Artistici. Tea Editore. pp. 403-404.

8 GRASSI, Luigi. Teorici e Storia della Critica d'Arte. Parte Prima - Dall'Antichità a tutto il Cinquecento com due saggi introduttivi. Multigrafica Editrice, Roma, 1970: "Imitazione è, dunque, nel Cinquecento più che mai l'equivalente del 'verosimile' aristotélico. Sembra talora che 'imitare' voglia semplicemente dire 'rappresentare' le cose quali sono: come quando il Dolce afferma che il pittore che più si avvicina alla natura "è più perfetto Maestro". Ma al di là delle differenze di significato che la parola imitazione poteva assumere presso i diversi autori, resta ben ferma la comune esigenza a distinguere, per così dire, tra uma rappresentazione oggettiva del vero ed uma imitazione ideale della natura, possibile nel riferimento della natura stessa, così come si presenta, ad un principio universale superiore, o Idea del Bello". 
simularem algo que não existe9. Porém, se para Platão o mundo natural nada mais é do que uma cópia do mundo perfeito das Idéias, que está além dele, foi Cícero quem observou não estar a idea, num lugar intangível e nem podendo ser alcançada pela experiência, porém, encontrando-se somente no espírito do artista.

Ainda de acordo com Grassi, estes dois momentos descrevem duas elaborações platônico-aristotélicas do conceito de imitação, significantes nos tratados de arte do século XVI, a distinção entre ritrarre e imitare, que será melhor argumentada por Vincenzio Danti em seu Trattato delle perfette proporzioni, publicado em 1567. No termo ritrarre, o pintor representa as coisas "enquanto são", reconhecendo-as como perfeitas. No imitare, o artista, para atingir a perfeição, imitaria as coisas como elas "deveriam ser", corrigindo as imperfeições naturais. Grassi afirma que estes dois termos formam um código interpretativo. Assim, o ritrarre referir-se-ia às coisas vistas, por si mesmas, com toda perfeição, o imitare, significaria representar uma coisa não somente do modo como outros possam ver nela a coisa imitada, em sua imperfeição, mas fazê-la como ela teria de ser em toda sua perfeição. A “imitação" seria, nesse sentido, um modo de operar através do qual evitar-se-ia a coisa imperfeita aproximando-se assim da idéia de perfeição.

São pertinentes ainda a estes dois momentos da imitação, os argumentos colocados por Platão no Sofista, que contrapõe "imitação icástica" (em relação às coisas que se encontram na natureza) e "imitação fantástica" (onde o pintor corrige com seu engenho e invenção, os defeitos da natureza). Conceitos que G. Comanini vai retomar em seu tratado Il Figino, de 1591.

Pode-se dizer que, quanto a esse aspecto da teoria artística veneziana, há uma confluência de conceitos aristotélicos e platônicos: mimesis e a noção de Idea. O primeiro conceito decorre da experiência com a natureza. O outro, de uma idealização que se constitui no interior do artista.

9 É válido relembrar a história da estátua de Atenas construída por Fídias, contendo proporções inexatas. Quando observada no nível do chão, as deformações era visíveis. Ao ser colocada na altura exata para a qual foi encomendada, as proporções eram corrigidas. O exemplo de Fídias talvez tivesse dado a Platão argumentos para refutar as artes da imitação. 


\section{Bibliografia}

DOLCE, Lodovico. Dialogo della Pittura, intitolato L'Aretino. in Trattati d'Arte del Cinquecento - Fra Manierismo e Controriforma. Vol. I. Bari, Gius. Laterza e Figli, 1960.

GRASSI, Luigi e PEPE, Mario. Dirionario dei Termini Artistici. Tea Editore.

GRASSI, Luigi. Teorici e Storia della Critica d'Arte. Parte Prima - Dall'Antichità a tutto il Cinquecento com due saggi introduttivi. Multigrafica Editrice, Roma, 1970.

PINO, Paolo. Dialogo di Pittura di Messer Paolo Pino nuovamente dato em luce. In Vinegia per Pauolo Gherardo, MDXLVIII. Edição fac-símile de 1548 (com nota de Giorgio Nicodemi), Milão, 1945. 